\title{
Optimal Radial Motor Nerve Conduction Study Using Ultrasound in Healthy Adults
}

\author{
Jungho Yeo, $\mathrm{MD}^{1}$, Yuntae Kim, $\mathrm{MD}^{1}$, Sooa Kim, MD${ }^{1}$, Kiyoung $\mathrm{Oh}, \mathrm{MD}^{1}$, Hyungdong Kang, MD² \\ ${ }^{1}$ Department of Rehabilitation Medicine, Soonchunhyang University Cheonan Hospital, \\ Soonchunhyang University College of Medicine, Cheonan; ${ }^{2}$ Department of Rehabilitation Medicine, \\ Soonchunhyang University Bucheon Hospital, Soonchunhyang University College of Medicine, Bucheon, Korea
}

Objective To obtain reference values, to suggest optimal recording and stimulation site for radial motor nerve conduction study (RmNCS), and to analyze the correlation among RmNCS parameters, demographics and ultrasonography (US) findings.

Methods A total of 55 volunteers participated in this study. We hypothesized that 'lateral edge of spiral groove (A)' was the optimal stimulation site, and the 'largest cross-sectional area (CSA) of extensor indicis proprius (EIP) muscle (B)' was the optimal recording site. The surface distance between ' $\mathrm{A}$ ' and the lateral epicondyle of the humerus divided by upper arm length, was named the spiral groove ratio. The surface distance between ' $\mathrm{B}$ ' and the ulnar styloid process divided by forearm length, was named the EIP ratio. Using US, we identified these sites, and further conducted RmNCS.

Results Data was collected from 100 arms of the 55 volunteers. Mean amplitude and latency were $5.7 \pm 1.1 \mathrm{mV}$ and $5.7 \pm 0.5 \mathrm{~ms}$, respectively, at the spiral groove, and velocity between elbow and spiral groove was 73.7 \pm 7.0 $\mathrm{m} / \mathrm{s}$. RmNCS parameters correlated significantly with height, weight, arm length, and CSA of the EIP muscle. Spiral groove ratio and EIP ratio were $0.338 \pm 0.03$ and $0.201 \pm 0.03$, respectively; both values were almost the same, regardless of age, sex and handedness.

Conclusion We established a reference value and standardized method of RmNCS using US. Optimal RmNCS can be conducted by placing the recording electrode $20 \%$ (about one-fifth) of forearm length from the ulnar styloid process, and stimulating at $34 \%$ (about one-third) of the humeral length from the lateral epicondyle.

Keywords Ultrasonography, Electromyography, Radial nerve

Received April 28, 2016; Accepted August 6, 2016

Corresponding author: Yuntae Kim

Department of Rehabilitation Medicine, Soonchunhyang University Cheonan Hospital, 31 Suncheonhyang 6-gil, Dongnam-gu, Cheonan 31151, Korea. Tel: +82-41-570-2220, Fax: +82-41-570-2776, E-mail: simon108@naver.com

ORCID: Jungho Yeo (http://orcid.org/0000-0002-8583-2943); Yuntae Kim (http://orcid.org/0000-0003-4063-4692); Sooa Kim (http://orcid.org/00000003-1578-0452); Kiyoung Oh (http://orcid.org/0000-0002-1886-5462); Hyungdong Kang (http://orcid.org/0000-0001-8599-4822).

(a) This is an open-access article distributed under the terms of the Creative Commons Attribution Non-Commercial License (http://creativecommons.org/ licenses/by-nc/4.0) which permits unrestricted noncommercial use, distribution, and reproduction in any medium, provided the original work is properly cited. Copyright $\odot 2017$ by Korean Academy of Rehabilitation Medicine 


\section{INTRODUCTION}

In clinical practice, radial nerve conduction study (NCS) is performed less frequently than the median and ulnar NCS. For patients having weak elbow extension, wrist drop or finger drop, electrophysiological evaluation of the radial nerve helps the physician to localize the lesion, assess the underlying pathophysiology, and provide useful information to the patient [1-4]. Despite its clinical significance, radial motor NCS is a difficult procedure, even for a skilled electromyographer, since the placement of recording electrodes is technically more difficult than it is for median or ulnar nerves. This is because the recording site, the extensor indicis proprius (EIP), is not as anatomically prominent as a thenar or hypothenar group, and is not a well-isolated muscle distinct from other radially innervated muscles. Also, since the radial nerve winds around the humerus and has a complex course through the forearm, it may be difficult to find a proper stimulation site, and to obtain similar responses at various stimulation sites along the course of the radial nerve.

Several studies have been done to establish an ideal technique for accurate NCS of the radial motor nerve [5-9]. However, the type of recording electrode (needle or surface) and placement sites (such as EIP, brachioradialis and extensor digitorum communis muscles) differ among the various researchers. Additionally, there are no standardized methods and reference values of compound muscle action potential (CMAP) amplitude for radial nerve, with values varying from 2 to $5 \mathrm{mV}[1-5,8,9]$.

Although some studies suggest ideal stimulation or recording sites for NCS using ultrasound (US) [10-13], others suggest the safest approaches for needle electrode insertion [14-16], studies of radial motor NCS have not been performed. Therefore, we used US to identify the optimal stimulation site of the radial nerve at the lateral edge of the spiral groove (radial sulcus), and with the recording electrode placement on the EIP muscle. Radial motor NCS were conducted according to the result of US evaluation. This study aimed to obtain normal reference values for radial motor NCS, to suggest the optimal method for recording electrode placement and optimal stimulation site for radial motor NCS, and to analyze the correlations among NCS parameter, demographics and US findings.

\section{MATERIALS AND METHODS}

\section{Subjects}

Sixty healthy volunteers were recruited through advertisements placed on bulletin boards. Participants with prior history of trauma of the arm, previous surgery to the cervical spine or upper extremity, neurologic abnormalities or significant systemic disease such as diabetes mellitus, chronic kidney disease, thyroid disease, rheumatoid arthritis and malignancy (which can affect the function of peripheral nerves) were excluded from the study. From the recruited subjects, 5 volunteers were excluded because 3 had elevated hemoglobin Alc level, and 2 showed abnormal thyroid function test in their blood test. Finally, 55 volunteers were included in this study. Demographic data, including age, sex, height, weight, body mass index (BMI) and dominant hand (right or left), were collected.

The present study was approved by Soonchunhyang University Cheonan Hospital Institutional Review Board (No. 2015-10-029-001). All participants provided informed consent in accordance with the guidelines of the ethics committee.

\section{Ultrasound evaluation}

Subjects underwent ultrasound in the supine position, with the forearm fully pronated, the elbow slightly flexed (about $30^{\circ}$ ), and the arm slightly abducted (about $30^{\circ}$ ). Before US evaluation, arm length was measured with a standard tape ruler. Forearm length was defined as the straight line distance between the ulnar styloid process and the lateral epicondyle of the humerus. Upper arm length was defined as the straight line distance between the lateral epicondyle of the humerus and the most lateral point of the acromion process of the scapula.

After arm length measurement, an US scan of all subjects was performed using an E-CUBE 9 Diamond US system (Alpinion, Seoul, Korea) with a high density linear array transducer (3-12 MHz). The US settings were optimized for imaging: frequency, depth and focus zone. All measurements were performed by a single ultrasonographer having more than 5 years experience in musculoskeletal US.

For detecting the ideal stimulation site of the radial nerve at the spiral groove level, an US probe was placed along the straight line between the lateral epicondyle of the humerus and the most lateral point of the acromion. 
The probe was tracked along the proximal and distal directions, until the radial nerve was located at its most superficial level above the humerus. After detection of the 'spiral groove site', the surface distance between this site and the lateral epicondyle of the humerus was measured (Fig. 1). Subsequently, this distance was divided by the upper arm length, and was duly named the 'spiral groove ratio'.

Next, for identification of the ideal recording electrode placement site, US evaluation of the EIP muscle was conducted in a cross-sectional view at the distal forearm. To obtain accurate measurements, the transducer was held perpendicular to the muscle with minimal pressure.
Subsequently, the probe was tracked in the proximal and distal directions along the straight line between the ulnar styloid process and the lateral epicondyle of the humerus, to locate the thickest site of EIP muscle. On the basis of this site, the largest cross-sectional area (CSA) of the EIP muscle was measured (Fig. 2). To reduce error, CSA was measured twice, and the average value was calculated. After detection of the 'EIP muscle site', the surface distance between this site and the ulnar styloid process was measured, and this distance was divided by the forearm arm length. This was named the 'EIP ratio'.
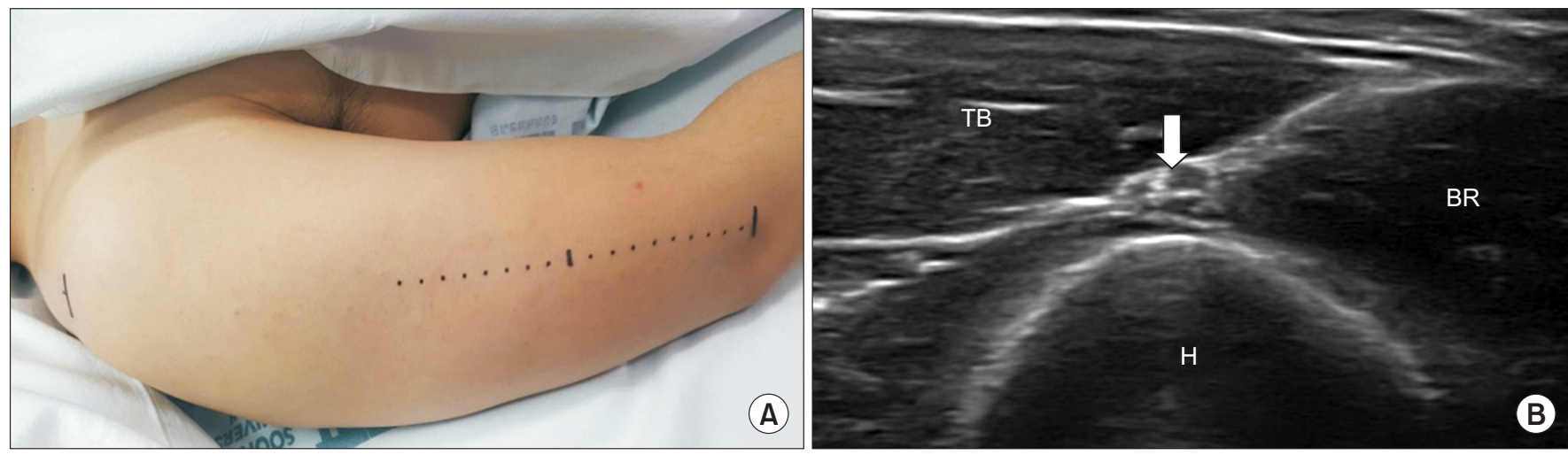

Fig. 1. Ultrasonographic evaluation of radial nerve at the spiral groove. (A) The probe was placed along the straight line between lateral epicondyle of humerus and most lateral point of acromion process of scapula. The probe was then tracked in the proximal and distal directions, until the radial nerve was located at its most superficial level above the humerus. (B) Ultrasonographic evaluation of radial nerve which placed most superficially between TB and BR at the lateral edge of spiral groove (arrow, radial nerve with brachial artery). $\mathrm{H}$, humerus; TB, triceps brachii; BR, brachialis.
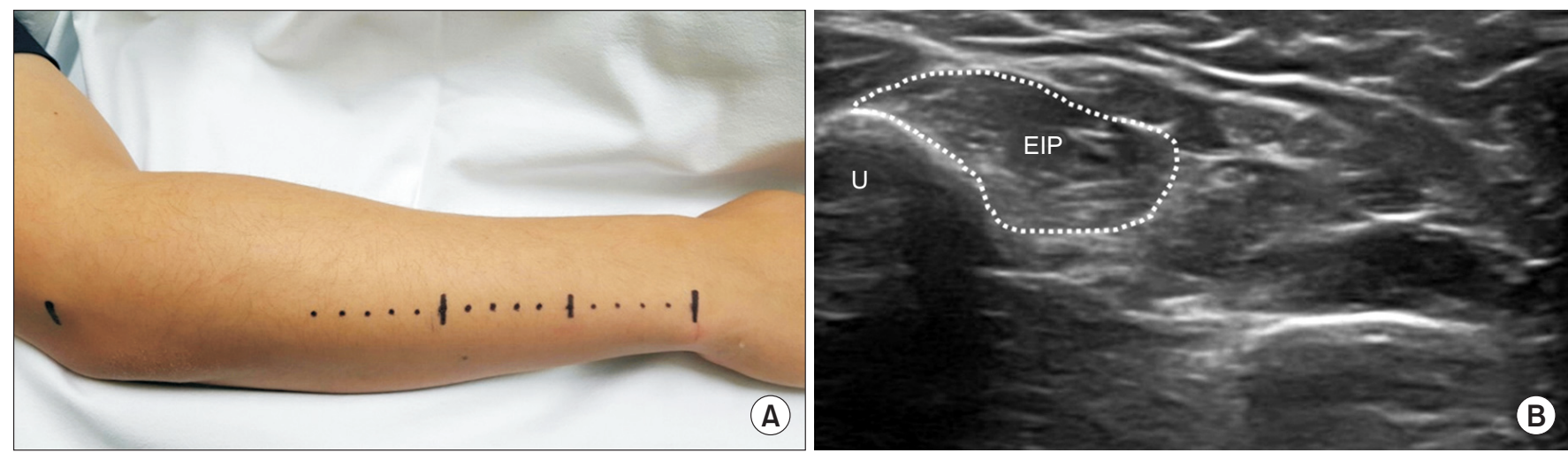

Fig. 2. Ultrasonographic evaluation of EIP muscle. (A) The probe was placed along the straight line between styloid process of ulna and lateral epicondyle of humerus. The probe was then tracked in the proximal and distal direction to find the thickest site of EIP muscle. On the basis of that site, the largest cross-sectional area (CSA) of EIP muscle was measured. To reduce error, CSA was measured twice, and the average value was calculated. (B) Ultrasonographic evaluation of EIP muscle to find largest CSA site (dotted line, CSA of EIP). EIP, extensor indicis proprius; U, ulna. 


\section{Radial motor nerve conduction study}

After US evaluation, radial motor NCS was conducted using Medelec Synergy electromyography 11.0 (Oxford Instrument Medical Ltd., Surrey, UK), with the following settings: silver-chloride circular surface electrode (10 $\mathrm{mm}$ in diameter); percutaneous bipolar stimulator; gain, $5 \mathrm{mV} /$ division; sweep speed, $5 \mathrm{~ms} /$ division; bandwidth filters of $10 \mathrm{kHz}$ (high) and $3 \mathrm{~Hz}$ (low). Using a heating pad, the extremities were warmed to $32^{\circ} \mathrm{C}$ and maintained at this temperature throughout the examination. NCS was performed in the same position as the previous US evaluation. The wrist was taped to an arm board to prevent motion during stimulation, which could result in a change in the CMAP morphology. Current intensity (50-70 $\mathrm{mA})$ and duration (0.1-0.5 ms) were increased until the amplitude of recorded potential reached a plateau, i.e., the maximal stimulus. Additional stimulations were subsequently delivered at approximately $20 \%-33 \%$ above the maximal intensity, which is the supramaximal stimulus. CMAP amplitude was measured from the initial positive peak to the negative peak because there is almost always an initial positive deflection caused by volumeconducted potential from other nearby radial-innervated muscles. CMAP onset latency was also set at the initial positive peak. Distance was measured using the length from the center of the electrode surface.

The E1 electrode was placed on the previously marked EIP muscle site. The E2 electrode was placed on the styloid process of the ulna. Using a bipolar surface stimulator, supramaximal stimulation was applied at the following nerve sites: forearm $(6 \mathrm{~cm}$ proximal to the $\mathrm{E} 1$ electrode, lateral to the extensor carpi ulnaris muscle); elbow (antecubital fossa of humerus between brachioradialis muscle and tendon of biceps brachii muscle); and spiral groove (previously marked spiral groove site by US evaluation).

Assuming that stimulation at the spiral groove was the optimal method with fewer technical errors, stimulation at the spiral groove was performed first. Based on the value obtained from spiral groove stimulation, stimulation at the forearm and elbow was performed. Finally, additional sensory and motor NCS of median and ulnar nerve was conducted using a general method.

\section{Statistical analysis}

NCS parameters and demographic data were expressed as mean \pm standard deviation. The data was tested for a normal distribution using the Shapiro-Wilk test. The independent sample t-test was used to compare the NCS parameters and demographic data between men and women, and right and left hand. The correlations among NCS parameters, demographic data and US findings were assessed using Pearson correlation coefficients. All analyses were performed using SPSS ver. 19.0 (IBM SPSS, Armonk, NY, USA). A p-value of 0.05 or less was considered statistically significant.

\section{RESULTS}

Measurements from a total $100 \mathrm{arms}$ of 55 volunteers (31 men and 24 women; mean age, 45.0 years; age range, 17 76 years) were collected. Of these, 90 data were obtained from both upper extremities of 45 volunteers. However, 10 data from 10 volunteers were obtained only from one side. Of the 10 data values, 6 were excluded since they were diagnosed with focal neuropathy on one side (5 patients showed carpal tunnel syndrome, 1 patient showed cubital tunnel syndrome), and 4 volunteers refused examination on the opposite side due to pain. Demographic data of volunteers are shown in Table 1. There was significant difference between men and women in height, weight, BMI, upper arm length and forearm length.

Arm length and US measurements are summarized in

Table 1. Subject characteristics

\begin{tabular}{|cc}
\hline \multicolumn{1}{c}{ Characteristic } & Value \\
\hline Gender (male:female) & \\
Male & 31 \\
\hline Female & 24 \\
\hline Age $(\mathrm{yr})$ & $45.0 \pm 13.7$ \\
Height $(\mathrm{cm})$ & $164.5 \pm 8.9$ \\
\hline Weight $(\mathrm{kg})$ & $65.9 \pm 13.3$ \\
\hline Body mass index $\left(\mathrm{kg} / \mathrm{m}^{2}\right)$ & $24.3 \pm 3.6$ \\
\hline Dominant hand & \\
\hline Right & 52 \\
\hline Left & 3 \\
\hline Examined hand & 53 \\
Right & 47 \\
\hline Left & \\
\hline
\end{tabular}

Values are presented as number or mean \pm standard deviation. 
Table 2. Arm length and ultrasonographic measurements

\begin{tabular}{lccccccc}
\hline & $\begin{array}{c}\text { Total } \\
(\mathbf{n}=\mathbf{1 0 0})\end{array}$ & $\begin{array}{c}\text { Men } \\
(\mathbf{n = 5 5})\end{array}$ & $\begin{array}{c}\text { Women } \\
(\mathbf{n}=\mathbf{4 5})\end{array}$ & $\mathbf{p}$-value & $\begin{array}{c}\text { Right } \\
(\mathbf{n = 5 3})\end{array}$ & $\begin{array}{c}\text { Left } \\
(\mathbf{n}=\mathbf{4 7})\end{array}$ & p-value $^{\text {b) }}$ \\
\hline Stimulation site & & & & & & & \\
Upper arm length $(\mathrm{cm})$ & $30.4 \pm 2.1$ & $31.6 \pm 1.8^{*}$ & $29.0 \pm 1.5^{*}$ & 0.000 & $30.5 \pm 2.1$ & $30.3 \pm 2.1$ & 0.762 \\
\hline Spiral groove site $(\mathrm{cm})$ & $10.3 \pm 1.1$ & $10.6 \pm 1.0^{*}$ & $9.8 \pm 1.1^{*}$ & 0.000 & $10.2 \pm 1.1$ & $10.3 \pm 1.2$ & 0.677 \\
Spiral groove ratio & $0.338 \pm 0.03$ & $0.337 \pm 0.03$ & $0.339 \pm 0.03$ & 0.801 & $0.336 \pm 0.03$ & $0.340 \pm 0.03$ & 0.460 \\
Recording site & & & & & & & \\
Forearm length (cm) & $23.5 \pm 1.8$ & $24.6 \pm 1.5^{*}$ & $22.1 \pm 1.0^{*}$ & 0.000 & $23.6 \pm 1.8$ & $23.4 \pm 1.8$ & 0.660 \\
EIP muscle site $(\mathrm{cm})$ & $4.7 \pm 0.8$ & $4.9 \pm 0.8^{*}$ & $4.5 \pm 0.8^{*}$ & 0.006 & $4.7 \pm 0.8$ & $4.7 \pm 0.8$ & 0.748 \\
CSA of EIP $\left(\mathrm{cm}^{2}\right)$ & $0.79 \pm 0.18$ & $0.86 \pm 0.19^{*}$ & $0.69 \pm 0.10^{*}$ & 0.000 & $0.79 \pm 0.19$ & $0.78 \pm 0.17$ & 0.635 \\
EIP ratio & $0.201 \pm 0.03$ & $0.199 \pm 0.03$ & $0.203 \pm 0.03$ & 0.592 & $0.202 \pm 0.03$ & $0.200 \pm 0.03$ & 0.839 \\
\hline
\end{tabular}

Values are presented as number or mean \pm standard deviation.

EIP, extensor indicis proprius; CSA, cross-sectional area.

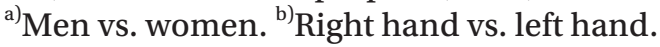

${ }^{*} \mathrm{p}<0.05$, between men and women.

Table 3. Results of radial motor nerve conduction study

\begin{tabular}{|c|c|c|c|c|c|c|c|}
\hline & $\begin{array}{c}\text { Total } \\
(\mathbf{n}=100)\end{array}$ & $\begin{array}{c}\text { Men } \\
(n=55)\end{array}$ & $\begin{array}{l}\text { Women } \\
(n=45)\end{array}$ & p-value $e^{\text {a) }}$ & $\begin{array}{c}\text { Right } \\
(n=53)\end{array}$ & $\begin{array}{c}\text { Left } \\
(n=47)\end{array}$ & p-value ${ }^{\text {b) }}$ \\
\hline \multicolumn{8}{|l|}{ Forearm level } \\
\hline Latency (ms) & $2.0 \pm 0.2$ & $2.0 \pm 0.2^{*}$ & $1.9 \pm 0.2^{*}$ & 0.013 & $2.0 \pm 0.2$ & $2.0 \pm 0.2$ & 0.098 \\
\hline Amplitude (mV) & $6.0 \pm 1.1$ & $6.4 \pm 1.1^{*}$ & $5.5 \pm 0.8^{*}$ & 0.000 & $6.2 \pm 1.1$ & $5.8 \pm 0.9$ & 0.053 \\
\hline \multicolumn{8}{|l|}{ Elbow level } \\
\hline Latency (ms) & $4.3 \pm 0.4$ & $4.5 \pm 0.4^{*}$ & $4.1 \pm 0.3^{*}$ & 0.000 & $4.4 \pm 0.4$ & $4.3 \pm 0.4$ & 0.392 \\
\hline Amplitude (mV) & $5.8 \pm 1.1$ & $6.2 \pm 1.1^{*}$ & $5.3 \pm 0.8^{*}$ & 0.000 & $6.0 \pm 1.1$ & $5.5 \pm 1.1$ & 0.057 \\
\hline Velocity (m/s) & $56.8 \pm 4.7$ & $56.9 \pm 4.7$ & $56.8 \pm 4.7$ & 0.962 & $57.2 \pm 4.4$ & $56.5 \pm 5.0$ & 0.472 \\
\hline \multicolumn{8}{|l|}{ Spiral groove level } \\
\hline Latency (ms) & $5.7 \pm 0.5$ & $6.0 \pm 0.4^{*}$ & $5.4 \pm 0.3^{*}$ & 0.000 & $5.7 \pm 0.5$ & $5.7 \pm 0.5$ & 0.666 \\
\hline Amplitude (mV) & $5.7 \pm 1.1$ & $6.1 \pm 1.2^{*}$ & $5.2 \pm 0.8^{*}$ & 0.000 & $5.9 \pm 1.1$ & $5.5 \pm 1.1$ & 0.086 \\
\hline Velocity (m/s) & $73.7 \pm 7.0$ & $72.9 \pm 6.4$ & $74.8 \pm 7.6$ & 0.195 & $74.6 \pm 7.3$ & $72.8 \pm 6.7$ & 0.218 \\
\hline
\end{tabular}

Values are presented as number or mean \pm standard deviation.

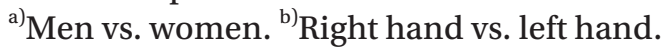

${ }^{*} \mathrm{p}<0.05$, between men and women.

Table 2. The mean upper arm and forearm length was $30.4 \pm 2.1 \mathrm{~cm}$ and $23.5 \pm 1.8 \mathrm{~cm}$, respectively. The distance between site of radial nerve at spiral groove level and lateral epicondyle of humerus was $10.3 \pm 1.1 \mathrm{~cm}$ and the spiral groove ratio was $0.338 \pm 0.03$. The largest CSA of EIP muscle was $0.79 \pm 0.18 \mathrm{~cm}^{2}$. Distance between site of the largest CSA portion of EIP muscle and styloid process of ulnar was $4.7 \pm 0.8 \mathrm{~cm}$ and EIP ratio was $0.201 \pm 0.03$. Significant differences were observed between men and women with respect to arm length, CSA of EIP muscle, and distance of spiral groove site and EIP muscle site.
However, the spiral groove ratio and EIP ratio were nearly the same, regardless of gender and side of examined hand.

The results of radial motor NCS are summarized in Table 3. At the spiral groove level, mean latency, amplitude, and velocity between elbow and spiral groove level were $5.7 \pm 0.5 \mathrm{~ms}, 5.7 \pm 1.1 \mathrm{mV}$, and $73.7 \pm 7.0 \mathrm{~m} / \mathrm{s}$, respectively. At the forearm level, mean latency, amplitude, and velocity between forearm and elbow level were $2.0 \pm 0.2 \mathrm{~ms}$, $6.0 \pm 1.1 \mathrm{mV}$ and $56.8 \pm 4.7 \mathrm{~m} / \mathrm{s}$, respectively. No significant differences were observed between NCS results of right 
Table 4. Correlation analysis between NCS parameters and subject characteristics

\begin{tabular}{lcccc}
\hline & \multicolumn{4}{c}{ Pearson correlation coefficient (r) } \\
\cline { 2 - 5 } & Latency $(\mathbf{m s})$ & Amplitude $(\mathbf{m V})$ & Velocity $(\mathbf{m} / \mathbf{s})$ & CSA $\left(\mathbf{c m}^{2}\right)$ \\
\hline Age & -0.186 & -0.034 & -0.034 & -0.065 \\
Height & $0.688^{*}$ & $0.238^{* *}$ & -0.036 & $0.400^{*}$ \\
Weight $(\mathrm{kg})$ & $0.505^{*}$ & 0.132 & 0.020 & $0.377^{*}$ \\
Upper arm length $(\mathrm{cm})$ & $0.666^{*}$ & 0.131 & -0.060 & $0.291^{*}$ \\
Forearm length $(\mathrm{cm})$ & $0.786^{*}$ & $0.240^{* *}$ & -0.137 & $0.346^{*}$ \\
CSA $\left(\mathrm{cm}^{2}\right)$ & $0.257^{*}$ & $0.394^{*}$ & 0.001 & 1 \\
\hline
\end{tabular}

Nerve conduction study (NCS) data at the spiral groove.

CSA, cross sectional area of extensor indicis proprius.

${ }^{*} \mathrm{p}<0.05,{ }^{* *} \mathrm{p}<0.01$.

and left hand. Comparison of genders revealed delayed latency and larger amplitude in men, but similar conduction velocity in both men and women.

The correlations among NCS parameters, demographic data and US findings are shown in Table 4. The CMAP amplitude had moderate positive correlation with CSA of EIP muscle ( $\mathrm{r}=0.394)$, but weak positive correlation with height $(\mathrm{r}=0.238)$ and forearm length $(\mathrm{r}=0.240)$. The CMAP latency had a strong positive correlation with height $(\mathrm{r}=0.688)$, upper arm length $(\mathrm{r}=0.666)$, and forearm length $(\mathrm{r}=0.786)$, a moderate positive correlation with weight $(\mathrm{r}=0.505)$, and weak positive correlation with CSA of EIP muscle $(r=0.257)$. Age had no significant correlation with NCS parameters. Spiral groove ratio and EIP ratio did not show any significant correlation with age, sex, height, arm length, and CSA of EIP muscle.

\section{DISCUSSION}

The present study established a reference value and standardized the NCS method of radial motor nerve using US. We also identified correlations among NCS parameters, demographics and US findings. Several studies have used US for electrophysiological study, but to our knowledge, this is the first study that employed US for radial motor NCS.

Previous research has suggested normal NCS reference values. A study by Kang et al. [8] suggested a reference value of radial motor NCS using surface electrodes in normal Korean adults. They reported that mean latency, amplitude at forearm, and velocity between forearm and elbow were $2.2 \pm 0.03 \mathrm{~ms}, 5.04 \pm 3.31 \mathrm{mV}$, and $71.12 \pm 14.94$ $\mathrm{m} / \mathrm{s}$, respectively. However, limitations in this study in- cluded a small number of subjects $(\mathrm{n}=30)$, and the study did not perform NCS according to the standardized methods.

We conducted radial motor NCS by standardized method using US with a larger number of participants. At the spiral groove level, mean latency, amplitude, and velocity between elbow and spiral groove level were $5.7 \pm 0.5$ $\mathrm{ms}, 5.7 \pm 1.1 \mathrm{mV}$, and $73.7 \pm 7.0 \mathrm{~m} / \mathrm{s}$, respectively. At the forearm level, mean latency, amplitude, and velocity between forearm and elbow level were $2.0 \pm 0.2 \mathrm{~ms}, 6.0 \pm 1.1$ $\mathrm{mV}$, and $56.8 \pm 4.7 \mathrm{~m} / \mathrm{s}$, respectively. Compared with the data of Kang et al. [8], our data indicated a higher average amplitude with smaller standard deviation, in spite of more participants. In other words, our method correctly reflects the summation of underlying individual muscle fiber action potentials, and hence accuracy was also higher.

We further evaluated the correlation among NCS parameters, subject characteristics and US findings. Radial motor NCS parameters correlated significantly with height, weight, arm length and CSA of EIP muscle. In contrast, age and sex did not show any significant correlation with CMAP parameters. Statistically significant differences were seen between men and women in CMAP latency ( $2.0 \pm 0.2 \mathrm{~ms}$ vs. $1.9 \pm 0.2 \mathrm{~ms})$ and amplitude $(6.4 \pm 1.1 \mathrm{mV}$ vs. $5.5 \pm 0.8 \mathrm{mV})$. These findings were consistent with previous studies where the motor amplitudes were greater in men, and motor conduction velocities were faster in women $[17,18]$. Theses gender difference could be explained by result of our correlation analysis, that men were generally bigger, heavier and had longer arm length than women, and was not because of the gender. In conclusion, our radial motor NCS results can be 
used as reference values, regardless of age, sex and side of examined hand.

Two hypotheses were studied to find an optimal method of radial motor NCS by devising spiral groove ratio and EIP ratio. First, we hypothesized that the lateral edge of the spiral groove was the optimal stimulation site for radial motor NCS. In the forearm, the radial nerve is located in the deep layer with nearby radial-innervated muscles, and the diameter of the radial nerve is much smaller than at the spiral groove $\left(4.61 \pm 0.88 \mathrm{~mm}^{2}\right.$ vs. $1.99 \pm 0.43 \mathrm{~mm}^{2}$ ) [19-21]. For these reasons, there may be several significant technical errors when stimulation is conducted at the forearm compared with the spiral groove, such as exaggerated CMAP response via volumeconducted potentials from nearby radial-innervated muscles, initial positive deflection with unclear onset latency, or lower CMAP amplitude caused by insufficient stimulation. In addition, stimulation at the forearm level usually requires a higher intensity and longer duration (approximately $>0.5 \mathrm{~ms}$ ) which results in more pain and discomfort to the patient. Therefore, we concluded that stimulation at the forearm had some limitations, and that the lateral edge of the spiral groove was the optimal stimulation site. We therefore recommend that stimulation at the spiral groove is conducted preferentially, and additional stimulation at the forearm and elbow level can be conducted on the basis of CMAP parameter at this level.

Our second hypothesis was that the optimal recording electrode placement site was at the largest CSA of EIP muscle. When recording CMAP via surface electrodes, the recording electrode is traditionally placed over the center of the muscle belly, usually the thickest muscle portion, and the reference electrode is placed over the corresponding tendon (belly-tendon montage). In conventional radial NCS, placement site of the recording electrode on the EIP muscle is 2 to $4 \mathrm{~cm}$, or about two fingerbreadths, proximal to the ulnar styloid process on the dorsal aspects of the forearm, near the lateral edge of the ulna $[1,2,4,5]$. However, arm length varies depending on the individual, as also the origin site and length of the EIP muscle. Therefore, we examined the EIP muscle using US to find the largest CSA. This is because the site of largest CSA is generally located in the middle portion of the muscle where the motor point usually presents, so that it could properly reflect the summation of underlying individual muscle fiber action potentials. Also, as it is distinct from other nearby muscles, volume-conducted potentials could be minimized.

Our method referred to a previous study. Hackl et al. [22] conducted an anatomic study regarding the course of the radial nerve at the posterior aspect of the humeral shaft. They found the ratio which divides humeral length by distance of the proximal edge of the olecranon fossa to lateral edge of the spiral groove was $3.1 \pm 0.31$, which was similar to our result $(2.98 \pm 0.27)$. Fleming et al. [23] conducted an anatomic study to identify the point at which the radial nerve passes from the posterior to the anterior compartment of the arm. They found that in almost every case, the radial nerve entered the anterior at a point within $5 \mathrm{~mm}$ of the junction of the distal and middle thirds of a line between the lateral epicondyle of the humerus to the most lateral point of the acromion. This finding was also similar to our result of spiral groove ratio $(0.338 \pm 0.03)$.

In contrast to the study of radial nerve, there were few anatomical studies of the EIP muscle. Cauldwell et al. [24] had examined the EIP muscle in 263 consecutive specimens. They found marked variations in size, origin, insertion, or all of these, occurred in 41 (15.6\%) of 263 specimens. In our study, the distance between the site of largest CSA of EIP muscle and styloid process of ulnar was variable $(3-7 \mathrm{~cm})$, similar to their findings. However, the EIP ratio was quite consistent at $0.201 \pm 0.03$, ranging from 0.18 to 0.24 . Therefore, we consider our method of radial motor NCS using spiral groove ratio and EIP ratio as an optimal standardized method which can be generally applicable.

There were some limitations in our study. First, we identified the stimulation site of the radial nerve using US only at the spiral groove level. This was because we believed that the lateral edge of the spiral groove was the optimal stimulation site. However, the study of the radial nerve at the forearm and elbow could also have clinical significance, and hence additional research is required. Second, we tried to find the approximate locations for the largest CSA. If we examined the EIP muscle with multiple axial-plane along the length of the muscle and the CSA of each plane was calculated, the result would be more accurate. However, this was not possible due to time constraints. Third, recruitment of more left-handed volunteers and above 60 years age would identify an additional correlation associated with patient handedness or age. 
In conclusion, our study proposed a reference value of radial motor NCS via a standardized method. As a standardized method, stimulation of the radial motor nerve could be conducted at $34 \%$ (about one-third) of humeral length from the lateral epicondyle, where the radial nerve was located at its most superficial level above the humerus and the recording electrode could be located at $20 \%$ (about one-fifth) of forearm length from the styloid process of the ulna, which is the largest CSA site of EIP muscle. Using our method, radial motor NCS can be conducted optimally, as compared to conventional techniques.

\section{CONFLICT OF INTEREST}

No potential conflict of interest relevant to this article was reported.

\section{ACKNOWLEDGMENTS}

This work was supported by the Soonchunhyang University Research Fund.

\section{REFERENCES}

1. Dumitru D, Amato AA, Zwarts MJ. Electrodiagnostic medicine. 2nd ed. Philadelphia: Hanley \& Belfus; 1995. p. 810-1, 1087-94.

2. Kimura J. Electrodiagnosis in diseases of nerve and muscle: principles and practice. 3rd ed. New York: Oxford University Press; 2001. p. 148-51, 717-8.

3. Mondelli M, Morana P, Ballerini M, Rossi S, Giannini F. Mononeuropathies of the radial nerve: clinical and neurographic findings in 91 consecutive cases. J Electromyogr Kinesiol 2005;15:377-83.

4. Preston DC, Shapiro BE. Electromyography and neuromuscular disorders. 3rd ed. Philadelphia: Elsevier Saunders; 2013. p. 331-45.

5. Lee HJ, DeLisa JA. Manual of nerve conduction study and surface anatomy for needle electromyography. Philadelphia: Lippincott Williams \& Wilkins; 2005. p. 55-6.

6. Jebsen RH. Motor conduction velocity of distal radial nerve. Arch Phys Med Rehabil 1966;47:12-6.

7. Papathanasiou ES, Zamba E, Papacostas SS. Radial nerve F-waves: normative values with surface record- ing from the extensor indicis muscle. Clin Neurophysiol 2001;112:145-52.

8. Kang SY, Ko YJ, Choi ES, Oh CS. Radial motor nerve conduction study using surface electrode in normal adults. J Korean Acad Rehabil Med 1992;16:385-9.

9. Trojaborg W, Sindrup EH. Motor and sensory conduction in different segments of the radial nerve in normal subjects. J Neurol Neurosurg Psychiatry 1969; 32:354-9.

10. Boon AJ, Bailey PW, Smith J, Sorenson EJ, Harper CM, Hurdle MF. Utility of ultrasound-guided surface electrode placement in lateral femoral cutaneous nerve conduction studies. Muscle Nerve 2011;44:525-30.

11. Kamm CP, Scheidegger O, Rosler KM. Ultrasoundguided needle positioning in sensory nerve conduction study of the sural nerve. Clin Neurophysiol 2009; 120:1342-5.

12. Oh CH, Park NS, Kim JM, Kim MW. Determination of an ideal stimulation site of the medial antebrachial cutaneous nerve using ultrasound and investigation of the efficiency. Ann Rehabil Med 2014;38:836-42.

13. Park BJ, Joeng ES, Choi JK, Kang S, Yoon JS, Yang SN. Ultrasound-guided lateral femoral cutaneous nerve conduction study. Ann Rehabil Med 2015;39:47-51.

14. Boon AJ, Alsharif KI, Harper CM, Smith J. Ultrasoundguided needle EMG of the diaphragm: technique description and case report. Muscle Nerve 2008;38:16236.

15. Lee SM, Kim K, Lee SM, Lee HS. Ultrasonographic evaluation of needle insertion site for the flexor pollicis longus. Ann Rehabil Med 2013;37:215-20.

16. Yang SN, Lee SH, Kwon HK. Needle electrode insertion into the tibialis posterior: a comparison of the anterior and posterior approaches. Arch Phys Med Rehabil 2008;89:1816-8.

17. Robinson LR, Rubner DE, Wahl PW, Fujimoto WY, Stolov WC. Influences of height and gender on normal nerve conduction studies. Arch Phys Med Rehabil 1993;74:1134-8.

18. Stetson DS, Albers JW, Silverstein BA, Wolfe RA. Effects of age, sex, and anthropometric factors on nerve conduction measures. Muscle Nerve 1992;15:1095104.

19. Won SJ, Kim BJ, Park KS, Yoon JS, Choi H. Reference values for nerve ultrasonography in the upper extremity. Muscle Nerve 2013;47:864-71. 
20. Brown JM, Yablon CM, Morag Y, Brandon CJ, Jacobson JA. US of the peripheral nerves of the upper extremity: a landmark approach. Radiographics 2016;36:452-63.

21. Vergara-Amador E, Ramirez A. Anatomic study of the extensor carpi radialis brevis in its relation with the motor branch of the radial nerve. Orthop Traumatol Surg Res 2015;101:909-12.

22. Hackl M, Damerow D, Leschinger T, Scaal M, Muller LP, Wegmann K. Radial nerve location at the posterior aspect of the humerus: an anatomic study of 100 specimens. Arch Orthop Trauma Surg 2015;135:152732.

23. Fleming P, Lenehan B, Sankar R, Folan-Curran J, Curtin W. One-third, two-thirds: relationship of the radial nerve to the lateral intermuscular septum in the arm. Clin Anat 2004;17:26-9.

24. Cauldwell EW, Anson BJ, Wright RR. The extensor indicis proprius muscle: a study of 263 consecutive specimans. Q Bull Northwest Univ Med Sch 1943;17: 267-79. 